\title{
Study on Renewal Effectivity according to the Extended AHP
}

\author{
Takeshi Kanao $^{\star}$, Fusachika Miyasaka ${ }^{\star}$ and Eizo Kinoshita** \\ ${ }^{*}$ F. M. Center, Building Management Executive Dept., \\ Yamatake Building Systems Co., Ltd. \\ 4-3-4, Shibaura, Minato-ku, Tokyo 108-0023 JAPAN \\ **Faculty of Urban Science, Meijo University \\ 4-3-3, Nijigaoka, Kani, GIFU 509-0261 JAPAN \\ \{tkanao, fmiyasak \}@ybs.yamatake.co.jp/kinoshit@urban.meijo-u.ac.jp
}

\begin{abstract}
In this study, air conditioner automatic controllers at 71 buildings were the subjects. "Renewal effectivity" was defined as the effectivity available from renewal, and its value was calculated by the AM (Absolute Measurement) method, an extension of AHP (Analytic Hierarchy Process), the inner dependence method, and the inner-outer dependence method. This paper reports the calculation results.
\end{abstract}

\section{Introduction}

In renewal of building facilities, decision factors and processes are diverse. It is important for attaining mutual consent with the decision maker to provide him or her with appropriate judgement data about the necessity of renewal: Renewal involves huge costs in comparison with the incomes of individuals, and allotment of the costs is fairly difficult to judge. As a means of judgement for renewal, the more clearer is the relativity between merits and demerits, it is thought that the more satisfaction to the decision may be obtained.

For this merit-demerit relativity, an analysis was made by the extended AHP using quantitative and qualitative data from the standpoints as a manufacturer, maintenance firm, and user. With the buildings being subjects of the analysis, a maintenance contract has been made concerning to the air conditioner automatic controllers, so it is possible to gather quantitative data about the equipment conditions at the time of maintenance at regular intervals. In addition, qualitative data were gathered by a questionnaire about renewal, and consolidated with the quantitative data obtained at the maintenance.

\section{Renewal effectivity}

The new index "renewal effectivity" was defined to assess the effectivity available from renewal of air conditioner automatic controllers among building facilities. This can be defined from the "renewal demand" (necessity for renewal) determined from the merits obtainable from the renewal and the "renewal costs" determined from the demerits (expenses and user attitude) involved in the renewal.

\subsection{Subject buildings (selection of alternatives)}

The selection of buildings as the subjects of analysis proceeded as follows. First, from among the buildings with which a maintenance contract was made, 128 buildings were selected on the condition that 10 to 20 years had elapsed after completion. Next, on the questionnaire stage about "renewal demand" described in next section, opinions about renewal were requested from the facility managers of the 128 buildings. The number of buildings from which adequate answers were obtained was 7.1 . As a result, this number of buildings were the alternatives of analysis. 
As an index of the merits obtainable from renewal, "renewal demand" was defined as shown in the hierarchy diagram in Figure 1.

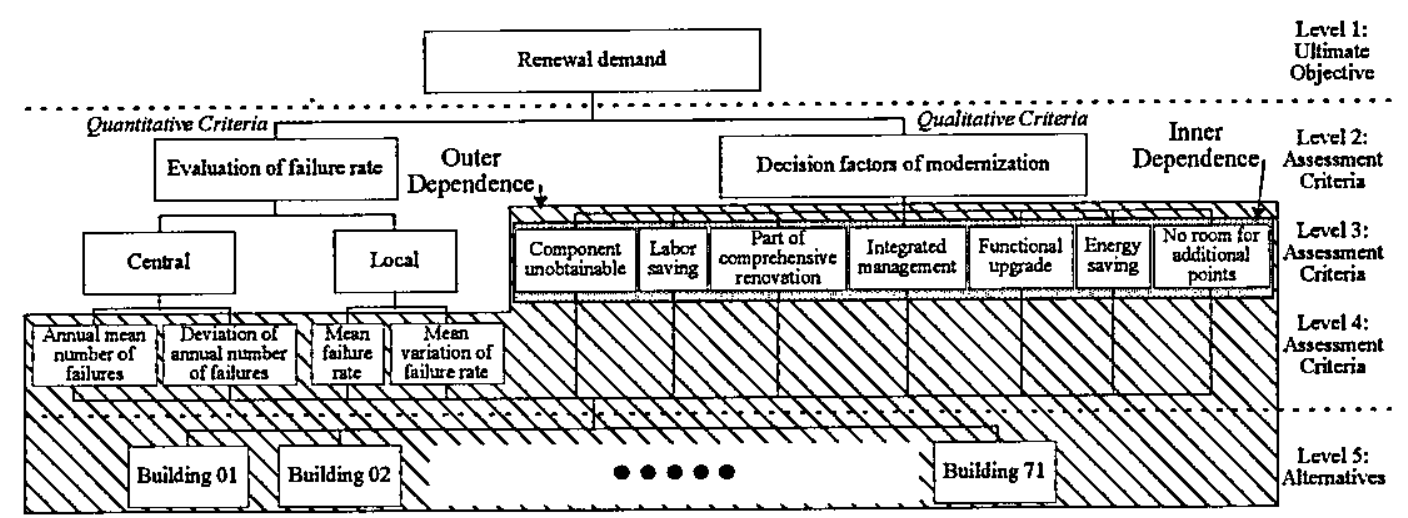

Figure 1 Hierarchy diagram of renewal demand

As shown at level 2, the "renewal demand" consists of "evaluation of failure rate" (a quantitative criterion) and "decision factors of modernization" (a qualitative criterion). The "evaluation of failure rate" is a quantitative criterion indicating the failure conditions of equipment, and is divided into "central" concerning to the central supervision controller and "local" concerning to the local equipment at level 3 . The items shown at level 4 are quantitative values related to the failures of equipment as the maintenance results. The "decision factors of modernization" is a qualitative criterion extracted from the questionnaire to the user about the motivation leading to actual renewal. As shown at level 3, these consist of 7 items. For these items, improvements can be expected from renewal.

\subsection{Definition of renewal costs}

As an index for the demerits of renewal, the "renewal costs" was defined as shown in the hierarchy diagram in Figure 2.

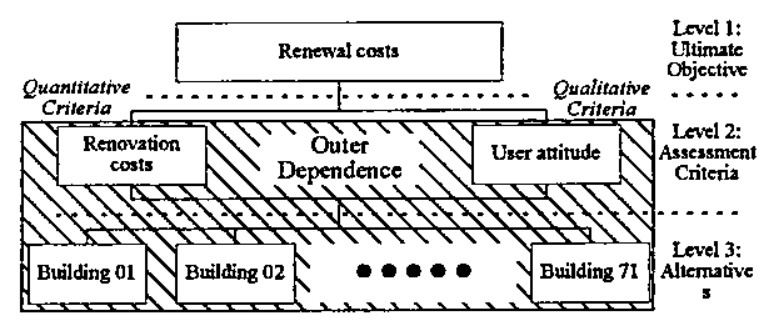

Figure 2 Hierarchy diagram of renewal costs

The "renewal costs" consist of "renovation costs" (a quantitative criterion) indicating the actual costs incurred by renewal and "user attitude" (a qualitative criterion) indicating the user's reluctance to renewal. The "renovation costs" are a quantitative criterion and calculated as the quantitative value of life cycle costs in the case of actual renovation and maintenance of an air conditioner automatic controllers. The "user attitude" is a qualitative value obtained from a questionnaire in the same manner as "renewal demand."

\subsection{Definition of renewal effectivity}

To take these two aspects into consideration, the "renewal effectivity" $E_{j}$ was defined by Equation (1) from the "renewal demand" $B_{j}$ and "renewal costs" $C_{j}$ defined above. This concept is a cost-benefit analysis in which the benefit is "renewal demand" and the costs are "renewal costs."

$$
E_{j}=\frac{B_{j}}{C_{j}} \quad(j=1,2, \cdots, 71) \quad j: \text { Building number }
$$




\section{Absolute assessment of renewal demand and renewal costs}

The AM method, an extension of AHP proposed by Saaty, was used to assess the 71 buildings. This technique is characterized by the fact that the evaluation of alternatives is carried out by absolute assessment instead of paired comparisons.

\section{W.1 Weighting of assessment items}

To calculate "renewal demand" and "renewal costs," one must do paired comparisons among the assessment items in the hierarchy diagrams. Part of the resuits is shown in Tables 1 and 2.

Table 1 Weighting of assessment items of renewal demand

\begin{tabular}{|c|c|c|c|c|c|c|c|c|}
\hline \multicolumn{9}{|c|}{ Level 3 (a qualitative criterion) } \\
\hline \multicolumn{9}{|l|}{ Decision factors of modernization } \\
\hline 0.5 & $\begin{array}{c}\text { Component } \\
\text { unobtainable }\end{array}$ & $\begin{array}{l}\text { Labor } \\
\text { saving }\end{array}$ & \begin{tabular}{c|} 
Part of \\
comprehensive \\
renovation
\end{tabular} & $\begin{array}{c}\text { Integrated } \\
\text { management }\end{array}$ & $\begin{array}{c}\text { Functional } \\
\text { upgrade }\end{array}$ & $\begin{array}{l}\text { Energy } \\
\text { saving }\end{array}$ & $\begin{array}{c}\text { No room for } \\
\text { additional } \\
\text { points }\end{array}$ & Weight \\
\hline Component unobtainable & 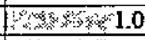 & 9.0 & 1.8 & 3.0 & 9.0 & 4.5 & 9.0 & $0 . \overline{409}$ \\
\hline Labor saving & 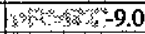 & (x) 1.0 & -5.0 & -3.0 & 1.0 & -2.0 & 1.0 & 0.045 \\
\hline Part of comprehensive & 4 & S.0 & now & 1.7 & 5.0 & 2.5 & 5.0 & 0.227 \\
\hline Integrated management & 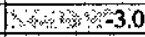 & 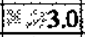 & 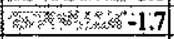 & 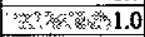 & 3.0 & 1.5 & 3.0 & 0.136 \\
\hline Functional upgrade & 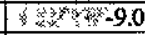 & $x=1.0$ & 永, & $\pi, y, j, 3,0,-3.0$ & 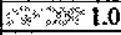 & .2 .0 & 1.0 & 0.045 \\
\hline Energy saving & 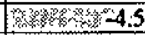 & 2.0 & 19. & 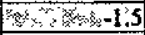 & 2,20 & 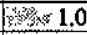 & 2.0 & 0.091 \\
\hline No room for additional points & 1 son. & -1.0 & 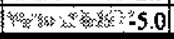 & $\cdots:-3.0$ & 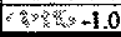 & $F_{3} x^{\prime}-2.0$ & 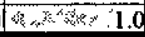 & 0.045 \\
\hline$\lambda$ max & & & & & & & & 7.000 \\
\hline c. I. & & & & & & & & 0.000 \\
\hline
\end{tabular}

Table 2 Weighting of assessment items of renewal costs

\begin{tabular}{|c|c|c|c|}
\hline \multicolumn{4}{|c|}{ Level 2} \\
\hline \multicolumn{4}{|l|}{ Renewal costs } \\
\hline & $\begin{array}{c}\text { Renovation } \\
\text { costs }\end{array}$ & User attitude & Weight \\
\hline Renovation costs & 1.0 & 1.0 & 0.500 \\
\hline User attitude & xis 1.0 & 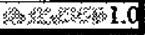 & 0.500 \\
\hline$\lambda \max$ & & & 2.000 \\
\hline C. I. & & & $0.000^{\circ}$ \\
\hline
\end{tabular}

\subsection{Weighting of absolute assessment levels}

Before assessing the alternatives, in the case of evaluation according to the qualitative criteria of the AM method, it is necessary to set absolute assessment levels for the assessment items and do paired comparisons among them. Absolute assessment levels were chosen according to the questionnaire results and weights were assigned to them according to the paired comparisons. The results of "component unobtainable" at level 3 of "renewal demand" and "user attitude" of "renewal costs" are shown Table 3.

Table 3 Weighting of absolute assessment levels

\begin{tabular}{|c|c|c|c|c|c|}
\hline \multicolumn{3}{|c|}{$\begin{array}{l}\text { Paired comparison of absolute criteria for } \\
\text { "energy saving" at level } 3 \text { of "renewal demand" }\end{array}$} & \multicolumn{3}{|c|}{$\begin{array}{l}\text { Paired comparison of absolute criteria for } \\
\text { "user attitude" of "renewal costs" }\end{array}$} \\
\hline \multicolumn{3}{|c|}{ Component unobtainable } & User attitude & & \\
\hline 0.20454547 & Embarrassed Don't know No problem & Weight & 0.5 & \begin{tabular}{|l|l|} 
Willing On the fence & Reluctant \\
\end{tabular} & Weight \\
\hline Embarrassed & 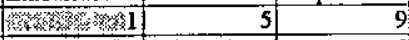 & 0.735 & Willing & 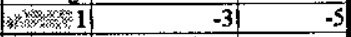 & 0.105 \\
\hline Don't know & 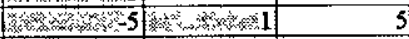 & 0.207 & On the fence & 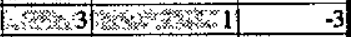 & 0.258 \\
\hline No problem & 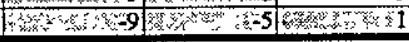 & 0.058 & Reluctant & 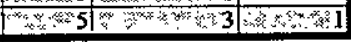 & 0.637 \\
\hline$\lambda \max$ & & 3.117 & $\lambda \max$ & & 3.039 \\
\hline C. I. & & 0.059 & C. I. & & 0.019 \\
\hline
\end{tabular}

\subsection{Absolute assessment of alternatives}

In the case of qualitative criteria, like as quantitative values for quantitative criteria, an absolute assessment of the alternatives takes place by use of the qualitative values determined in previous section. Part of the results is shown in Table 4. 
Table 4 Absolute assessment of alternatives (buildings)

\begin{tabular}{|c|c|c|c|c|c|c|c|c|c|c|}
\hline \multicolumn{8}{|c|}{$\begin{array}{l}\text { Absolute assessment of } \\
\text { "renewal demand" }\end{array}$} & \multicolumn{3}{|c|}{$\begin{array}{l}\text { Absolute assessment of } \\
\text { "renewal costs" }\end{array}$} \\
\hline \multicolumn{5}{|c|}{ Absolute measurement } & \multirow{3}{*}{$\begin{array}{l}\text { Deviation of } \\
\text { annual number } \\
\text { of failures }\end{array}$} & & & Absolute m & asurement & \\
\hline & Component & Labor saving & $\begin{array}{l}\text { Part of } \\
\text { comprehens }\end{array}$ & & & \multirow{2}{*}{$\begin{array}{c}\text { Mean failure } \\
\text { rate }\end{array}$} & \multirow{2}{*}{$\begin{array}{c}\text { Mean } \\
\text { variation of } \\
\text { failure rate }\end{array}$} & & $\begin{array}{c}\text { Renovation } \\
\text { costs }\end{array}$ & User attitude \\
\hline & unobtainable & 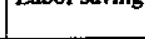 & renovatio & & & & & Building 01 & 83.2 & Wiling \\
\hline Building 01 & Emberrassi - & Don't know $\nabla$ & Needed & $\mathbf{v}$ & 0.33 & 4.85 & 3.22 & Building 02 & 445.5 & On the fents \\
\hline Building 02 & Embarrassi - & Don't know $\nabla$ & Needed & $\nabla$ & 0.33 & 15.94 & 6.93 & Building 03 & 251.8 & Reluctant $v$ \\
\hline Building 03 & Emberrassi & Needed & Not needed & $\bar{\nabla}$ & 0.66 & 0.25 & 4.73 & Building 04 & 119.5 & Rekuctant I \\
\hline Building 04 & No problen & Not needed $\nabla$ & Not needed & $\nabla$ & 0.33 & 1.22 & 3.29 & Building 05 & 155.2 & Rek \\
\hline Bujlding 05 & Dorit know & Don't know - & Not needed & $\Sigma$ & 0.33 & 1.71 & 3.66 & Building 06 & 508.3 & Rekuctant \\
\hline Building 06 & Embarrassi $\nabla$ & Not needed $\nabla$ & Not needed & $\nabla$ & 0.33 & 0.45 & 3.92 & & $:$ & \\
\hline Building 66 & Don't know $\bar{\nabla}$ & Don't know & eded & $\nabla$ & 0.33 & 1.69 & 5.63 & Building 66 & 85.2 & Reluctant \\
\hline Building 67 & Don't know $\nabla$ & Needed & Not needed & $\nabla$ & 0.66 & 0.3 & 4.22 & Building 67 & 160.2 & tant \\
\hline Building 68 & Embarrasse 7 & Not needec - & Not needed & $\nabla$ & 0.33 & 0 & 4.22 & Building 68 & 123.3 & Reluctant \\
\hline Building 69 & Enbarrasse $\nabla$ & Don't know - & Needed & $\Rightarrow$ & 0.66 & 0.66 & 4.03 & Building 69 & 233.7 & Witheng \\
\hline Building 70 & Don't know $\bar{\nabla}$ & Don't know - & Not needed & $\bar{\nabla}$ & 0.33 & 4.94 & 4.22 & Building 70 & 91.3 & Reluctant \\
\hline Building 71 & Embarrasse $\nabla$ & Don't know $\square$ & Not needed & $\nabla$ & 0.33 & & 4.22 & Building 71 & 63.5 & On the fenc : \\
\hline
\end{tabular}

\section{Dependence between assessment items (alternatives) and between assessment criterion levels}

In the following two cases, dependence occurs between assessment items (alternatives) in the hierarchical structure.

(1) Dependence exists between assessment items (alternatives) at the same assessment criterion level.

(2) Dependence exists between assessment criterion levels.

As an extension of AHP, Kinoshita presented instances of analysis by the inner dependence method for the case in which condition (1) alone holds, by the outer dependence method for the case in which condition (2) alone holds, and by the inner-outer dependence method for the case in which conditions (1) and (2) hold at the same time.

Then, the inner dependence method was used to analyze the influence due to the inner dependence between assessment items, and the inner-outer dependence method was used on that result to calculate the "renewal effectivity."

\subsection{Inner dependence method}

The inner dependence method is a technique used for the case where there is dependence between assessment items at the same assessment criterion level in order to make an analysis taking in the influence of the dependence. This technique is applied to 7 assessment items of the qualitative criterion at level 3 of

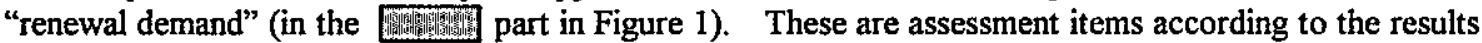
of a questionnaire about the motivation leading to renewal of air conditioner automatic controllers, and labor saving can be attained by integrated management as a matter of course. That is, "integrated management" has influence on "labor saving" and a dependence relationship exists between them.

By the way, as a method to find the direction and intensity of influence between factors, there is the DEMATEL (Decision Making Trial and Evaluation Laboratory) method. In this study, all the influence matrix calculated by the DEMATEL method were used to calculate the influence matrix representing the influence between the 7 assessment items above. In this way, a new weight for "renewal demand" was calculated. Now we can multiply the inner dependence's influence matrix $\mathbf{M}$ by the weights $\mathbf{W}\left(\mathbf{W}^{\mathbf{T}}=\right.$ $(0.409,0.045,0.227,0.136,0.045,0.091,0.045))$ obtained by conventional AHP in order to find the weights $\mathbf{W}_{\mathbf{I}}$ considering the dependence between factors. As a result,

$$
\mathbf{W}_{\mathbf{I}}^{\mathbf{T}}=(0.409,0.012,0.290,0.171,0.036,0.028,0.054)
$$

is obtained. Figure 3 shows a diagram showing the direction of influence by inner dependence. 


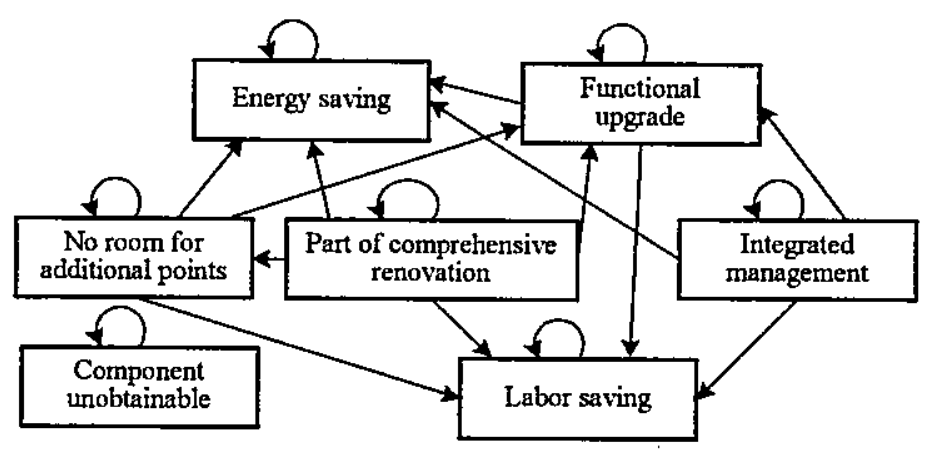

Figure 3 Direction of influence between assessment items

\subsection{Inner-outer dependence method}

The outer dependence method is employed in the case where there is dependence between assessment criterion levels, that is, it is a technique to carry out an analysis considering that influence. As described in Section 4, there is dependence between the lowest level of "renewal demand" and "renewal costs" and the alternative level (the $\$ 1 / 7$ part in Figures 1 and 2). That is to say, it is anticipated that weight assignment to the assessment criteria will differ from user to user of the buildings (dependence between different levels). Taking this difference in weight into account is equal to reflecting the difference in personal opinion about renewal among the users of the buildings if, for example, the alternatives are the buildings and the objective is renewal.

If the weights of the assessment items are to be altered for each alternative, it is necessary to have the user of each building assign a weight to the assessment items. In practice, however, this is impossible for consideration of the time and labor involved. By the way, there is DEA (Data Envelope Analysis) as a technique to calculate the relative efficiency values among alternatives using the optimum weights.

Then, the author calculated the optimum weights of each alternative for the assessment items at the lowest level by DEA and calculated the "renewal effectivity" by applying the inner dependence's influence matrix to the inner-outer dependence method together with these weights. The weights of the assessment items are shown in Figure 4 as to the variations when the inner dependence and outer dependence are considered.
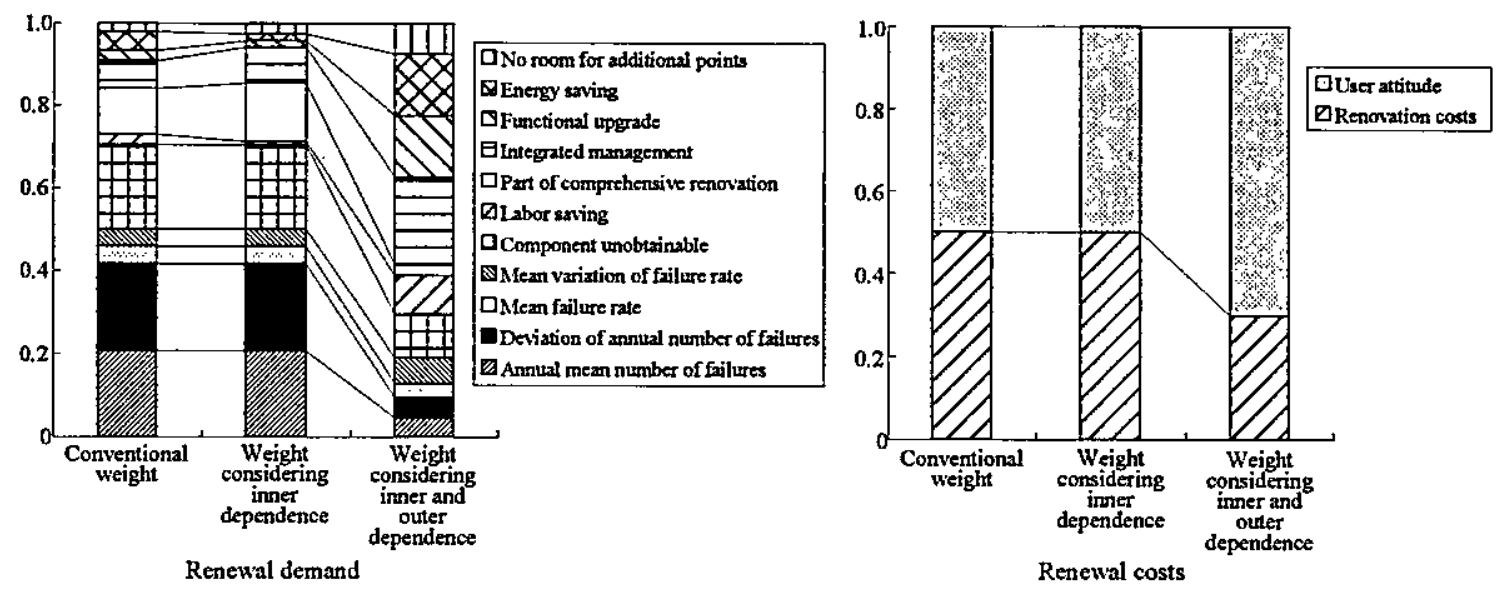

Figure 4 Comparison of weighting of assessment items

\subsection{Calculations of "renewal effectivity"}

The "renewal effectivity" has been calculated by the AM, inner dependence and inner-outer dependence methods, and the calculation results are shown in Figure 5 as Renewal effectivities (1), (2) and (3). Values are proportions to the maximum normalized to unity for each method. 


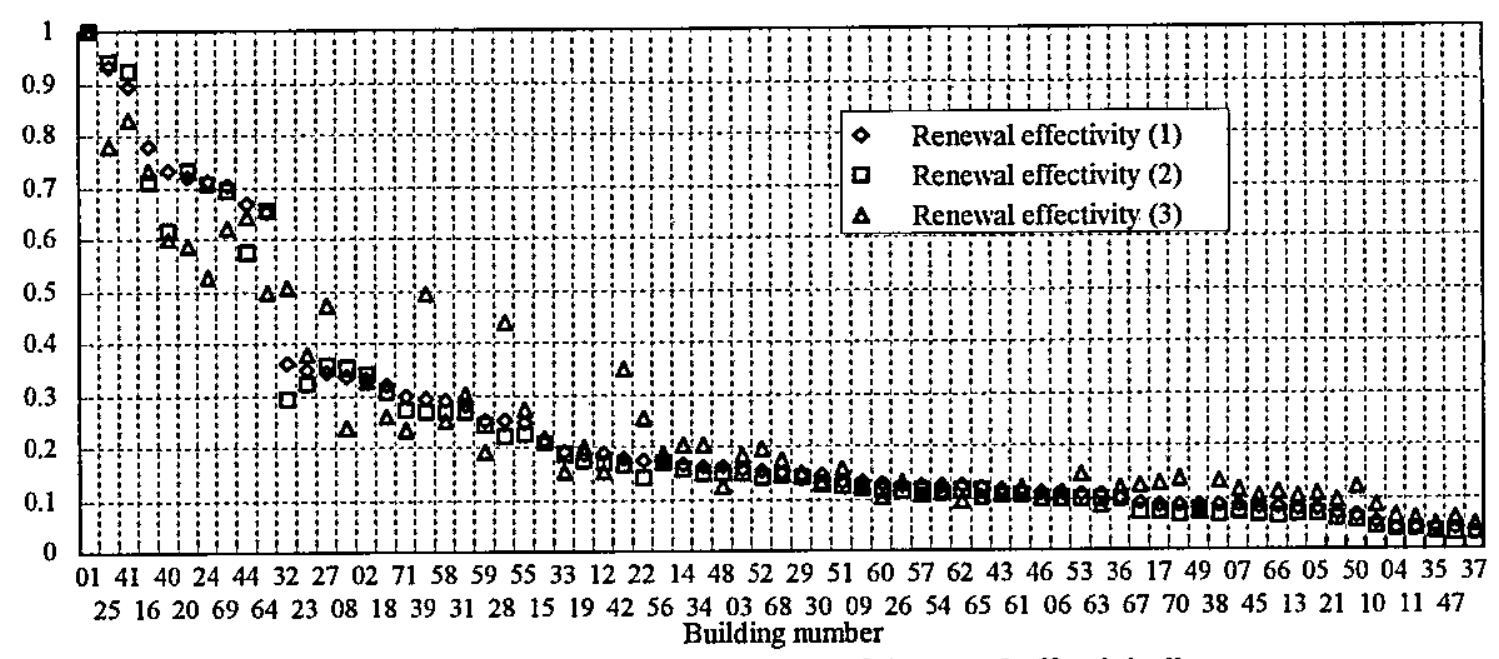

Figure 5 The calculation results of "renewal effectivity"

One sees that Renewal effectivity (3) differs from (1) and (2) at various places. This can be said a more actual result of weighting and assessment on the side of alternatives, that is, on the user side.

\section{Conclusion}

The author defined the "renewal effectivity" indicating the effectivity of renewal of the air conditioner automatic controllers of a building, and calculated its value by the AM method which was an extension of conventional AHP. For that, "renewal demand" and "renewal costs" consisting of quantitative data and qualitative data were defined, and an analysis was attempted on them from both merit and demerit sides.

In addition, the author fixed his eyes upon the dependence in the hierarchical structure, that is, the dependence between assessment items at the same level (inner dependence) as well as the dependence between assessment criteria levels (outer dependence), and made an analysis by the inner dependence method taking in the influence of inner dependence, and calculated the "renewal effectivity" by the innerouter dependence method taking in the weights as seen from each alternative. To the inner dependence's influence matrix, the DEMATEL method was applied which makes clear the direction and intensity of the influence between factors through a questionnaire. When carrying out the weight assignment from each alternative for outer dependence, the author did not use the weights by the analyst's subjective judgement but utilized the property of DEA of assigning weights so as to maximize the efficiency. In this way, he attempted to use objective weights.

\section{References}

E. Kinoshita, (1993) AHP Method And Applications, Sogogijyutu Center

E. Kinoshita, (1996) An Introduction to Management Science, Kindaikagakusha

E. Kinoshita, (1993) "A Study on Application of Analytic Hierarchy Process to Multi-Criteria Decision Making Problems," Traffic Engineering, Vol.26, No.6, 35-40

E. Kinoshita, F. Miyasaka, Y. Ishikawa, and Y. Azuma, (1995) "Cost-Benefit Analysis of Renewal Using the Extended of the Analytic Hierarchy Process," Operations Research, Vol.40, No.8, 17-22

K. Tone, (1993) Measurement And Improvement Of Management Efficiency, Nikkagiren

Saaty, T. L. (1990) Decision Making For Leaders, RWS 